\title{
Billets, Bombs and Babies: How the State Shaped the Narrative of Birth during the Second World War
}

\author{
Carly-Emma M. White \\ Nottingham Trent University, Nottingham,UK, carly-emma.white2010@my.ntu.ac.uk
}

\begin{abstract}
The health and social historiography of the Second World War is closely bound to the British national narrative of total war and the conflagration of the home front. The organisation of welfare structures during the conflict put enormous strain on existing socio-political constructs, if only because the state had to intervene in the day to day life of the nation on a scale not seen before. The prime initial concern was to minimise civilian death during enemy bombing, as losses in the hundreds of thousands were expected in the first few months of war. Plans were made to evacuate non-essential and vulnerable inhabitance from major cities and towns of. Displacement on this scale meant that medical and social services were similarly likely in need of significant reorganisation to match patient need and service location. In anticipation of this, the state created the Emergency Medical Service (EMS) to re-organise services within a supposedly more unified, planned national system. Using the Emergency Maternity Service as a case study, this paper seeks to explore the way in which the disruption of total war prompted the state to cross the threshold of the home into what was previously a private sphere - the family.
\end{abstract}

KEYWORDS: England and Wales, health and social care, maternity care, Second World War

\section{Introduction}

The existing historiographical work on the health and social arrangements of the war, including the Emergency Maternity Service, was published in the immediate post war years as part of a series of official war histories. As a result, they are rooted firmly in the post-war narrative, touched with more than a hint of the glow of victorious success. Furthermore, there are contradictions between authors which prove problematic. Ferguson and Fitzgerald claimed the Emergency Maternity Service performed well (Ferguson and Fitzgerald 1954). Yet their contemporary, Richard Titmuss' provides various examples of a shambolic service (Titmuss 1950). Titmuss's contributions are, however, tainted with his own reformist agenda and ergo his motivations for being more critical of the wartime administration are questionable. Furthermore, the success of any service is of course relative to how success is measured. The war histories take the Emergency Maternity Service out of the overall maternity care timeline and measure it in isolation. But since the maternity system before the war could not be deemed to have been operating ideally, with high levels of maternal mortality well into the 1930s, the emergency wartime model could not be expected to have been perfect. The claims and statistics used to form the basis of this paper have largely been extracted directly from archive material, particularly that from the National Archives. Thus far, over twelve hundred pages of correspondence, reports and data from the Ministry of Health war files have been examined. Additional data from the Chief Medical Officer reports and various local archives have also contributed.

The incursion into the realm of family by central both and local government social and health care machinery during the Second World War challenged pre-existing narratives of independence and self-reliance. Arguably, this creeping movement towards a more centralised system of welfare prompted a national conversation about what the nation would come to expect in the post-war world. The Beverage Report, published in 1942 and advocating the creation of the welfare state, is an oft cited example of the way in which the UK moved, during wartime, from post-Victorian individualism to post-war semi-socialism. How exactly this transition began to shape itself is a matter of some historiographical debate and is too broad a task for this paper. However, the creation of the National Health Service (NHS) in 1948 with care free at point of use is deemed one of the key moments in British social history and one on which a great deal of national identity is still pinned today. For this reason, to understand how the state was not only able, but was forced to enter the home during wartime, one must understand the pre-war health and social care situation. 
Access to institutional healthcare prior to the NHS system was dualistic in nature. One strand of the system belonged to former 'Poor Law' institutions. Most frequently these were former workhouses which, by the time of the war, were run and funded by local authorities. Despite this, access to municipal hospital care still involved an element of the old 'Poor Law' style assessment; the individual would have to be assessed by the local medical officer with care delegated based on the patient's need and means. This, combined with the enduring stigma of the 'old workhouse', meant that often, they were not a popular choice. Alternatively, there were voluntary hospitals which were run on a contributory basis both via charitable donations and work place contribution schemes. Although the treatment that could be accessed at such an institution varied across hospitals it was often of a high quality. Nick Hayes makes a strong case for the local affection for voluntary hospitals, evidenced by high levels of fundraising activity and popular public opinion (Hayes 2012). Nevertheless, Sally Sheard argues that by the late-1930s many of the independent hospitals were experiencing financial crises because their income could not keep pace with the costs of innovations in medical treatment (Sheard 2011, 428).

As war loomed, the administrative boundaries between the two hospitals systems had to be blurred in order to ensure that medical services could meet war-time demand and disruption. Provision had to be made for war casualties, both military and civilian, as well as all the peacetime undertakings of a hospital. The initial governmental concern was to minimise civilian death during enemy bombing, as losses in the hundreds of thousands were expected in the initial months of war. Plans were made to evacuate the major cities and towns of the elderly, the young, the vulnerable and pregnant women. Displacement on this scale meant that medical and social services became disjointed and were not always located where required. Consequently, the state created the Emergency Medical Service (EMS), which provided free treatment for war casualties, war workers and evacuees. Within the EMS was the Emergency Maternity Service, which oversaw the evacuation of women in the last weeks of pregnancy out from at risk areas, such as central London, and into more rural regions to give birth. As maternity care was not considered a part of war-related activity, the cost of the confinement was still expected to be met by the mother. The fees were set according to means and based on the pre-war model, but as might be imagined, retrieving these fees could be problematic as women moved around the county.

The maternity system offers an effective case study to evaluate how the state began to expand its boundaries during wartime. This is because there is quite distinct difference in its pre- and post-war form. While it is broadly acknowledged by historians of obstetric health that a rise in demand for hospital birth, exactly what the role of state-run wartime maternity provision was within this change, remains to be examined. This paper addresses this and examines how centrally managed maternity care during wartime sought to influence the choices facing women, and how it continued to do so after the war had ended. From September 1939 onward, pregnant women residing in at risk areas were evacuated out to rural reception areas, often a great distance from where they lived. Since these women were away from home and, thus, lacking traditional support networks, their birthing options were reduced, singularly, to the maternity institution. In this way, the British state shaped the narrative of birth in wartime by regulating and standardising the options available to many expectant mothers. Via the upheaval of war, it was also forced to construct the logistical structures within which confinement could be managed outside of family and kinship groups. The state became the de-facto midwife of the nation.

\section{The Pre-War Picture}

While it is not possible to typify the experiences of the interwar family in a paper of this size, it is important to touch on the challenges facing the families of this time. Economic downturn, and increasing levels of unemployment meant that working families were understandably reluctant to increase the number of mouths to feed, and after an initial post First World War 'baby boom', England and Wales saw a steady decline in births from 1920 onwards. The sustained economic slump that followed the end of war led to levels of unemployment that averaged 10.5\% in England and Wales for the entire interwar period (Hatten and Thomas 2010, 465). The impact was also heavily localised, as key traditional industries faltered and 
declined. While unemployment had been an issue before the Great War, it had never before tipped the ten percent mark. National unemployment peaked in 1933 at 23.5\%. Marks (1996, 13-14) notes in her work on the London boroughs, many working-class or impoverished women experienced pregnancy and motherhood in terms of basic survival. The health of an urban, working-class woman in the 1930s was constantly under pressure, because of poor nutrition and sub-standard living conditions.

It should be noted that at this point that although the 'hospital habit' was on the rise across health care generally, the majority of births still took place within the home, attended by a midwife or a local woman who called herself such. As data from Nottingham City demonstrates, the majority of babies were still being born at home. Some $75 \%$ of babies born in 1935 were still registered as a home birth. The cost of paying for a birth attended by a registered midwife or doctor could be prohibitive and a hospital birth would have been a greater expense still. So much so that despite the introduction of the 1902 Midwives Act, unregistered midwives continued to find work well into the early decades of the twentieth century. In 1917 the Lancaster Medical Officer of Health reported that 184 out of 613 babies born that year were delivered by an unqualified midwife. Furthermore, as the following examples from Nottingham's Oral History Collection show, there was a fondness for women in the community considered the 'midwife', whether they were qualified or not. This feeling persisted even though the 1929 and 1936 Midwives Acts further restricted the practice of unqualified midwifery. Birth was a local affair, and most frequently required the support of the local community. Whether it be the employment of a neighbourhood 'midwife' or the use of a local hospital funded by localised charity work or local taxation.

'Martha used to come, the midwife. They used to stop in bed a week in them days. She wasn't certified or anything but she was one of the good old midwives and it was only a few shillings for a confinement. I've heard m'mother say she used to give her sixpence a week until she got it paid off. She was a grand old lass.'

'we used to 'ave a women up from across, used to live across there, she wasn't a trained midwife but she used to look after anybody what had children...'

Another facet to the persistence of home birth in the interwar years is that prior to the availability of antibiotic drugs, evidence suggests that home births were actually the safer option. Irvine Loudon argues this was could be explained by increased interference by doctors in hospital births: for instance repeated vaginal examinations and overuse of forceps. This theory is borne out in the fact that a high percentage of maternal deaths were middle-class women (Loudon 1996). However, the very poorest women were also often referred to hospital by the local relieving officer as their homes were simply not in a good enough state for confinement to take place. As is the way in history, trying to sketch a general experience is problematic and there were multiple influencing factors on the pre-war maternity experience and the declining birth rate. What can be determined as fact though, is that women were having fewer children.

In 1937 the low birth was discussed in parliament with the Health Minster, Walter Elliot questioned as to how he was 'encouraging the birth rate in this country'. The inducement put forward on this occasion was the wider availability of analgesia during labour. While a reduction in pain may well have been an appealing prospect to the expectant mother, it had limitations as a policy. The approach the government took failed to examine the social and economic limitations on fertility with legislation and initiatives that focused on the clinical causes of high maternal mortality such as 1936 Midwives Act. While it was a welcome development in terms of patient safety, legislation of this nature has the unfortunate effect of laying the cause of increasing levels of maternal and infant mortality the door of the birth attendant whilst ignoring social factors.

In reality, the issues influencing women in their decision to not have children were not straight forward to resolve. In 1937 Tom Harrison and Charles Madge set up an organisation called MassObservation 'to study the society in which we live'. Its survey in 1943 attempted to understand the declining birthrate. What makes this study so fascinating is not so much that it provided answers as to why women were not having as many children as previously but that it provided a valuable insight into the world of motherhood at the time. The main categories into which women's response fell were 'help in the house', lack of money, fear of childbirth, housing issues and 'security'. Although the 
sample was not large, only about 200 interviews were conducted with married women of childbearing age, the responses all fell into these categories. Even at this high, broad level, it is possible to see that wider socio-political factors are impacting on day to day life and ergo the decision to expand a family. 'Security' is a particularly interesting example of this, the following responses are from women who were asked to expand on what they meant by 'security'.

Well, if I did have another, we want another girl. No boys to grow up ready for the next war. Glad we had only one; the world is not fit for civilized man. If we knew there'd be no more wars it'd be different. As things are we don't know what we're really in for.

The place isn't fit to bring up children. You might have another war very soon and it makes you feel is it worth the trouble to bring up children for cannon fodder.

Additionally, while fear of childbirth was not the most frequently mentioned reason for avoiding pregnancy, it was mentioned far more frequently in working-class districts. Thus once again illustrating the localised nature of the birth experience. The issue seemed to be that a pain-free or safer child birth experience was seen as the luxury of the middle classes. While this in isolation may not have necessarily prevented these women from having more children, their opinions do demonstrate a feeling of healthcare inequality.

"The hospitals for poor people should be made as comfortable as the rich nursing homes are. Rich people don't suffer, so why should we?"

"If you have the money you can have the best anesthetics and everything. That's not right is it?"

\section{The War Years}

General evacuation began on the $1^{\text {st }}$ September 1939 . The evacuation of maternity cases commenced on the second. The numbers expected were 140,000 but only in reality only 5600 departed from the London Metropolitan area when the day came. The programme was initially a 'trickle' scheme, with a certain number of mothers due to evacuated to specific areas each week according to when their baby was due. As uptake was limited, this was later supplemented by the 'signal' system where women would be evacuated once bombing had begun. By the summer of 1940, the service was being placed under increasing strain as night air raids escalated It was clear that there was a need for a broader evacuation to include Birmingham, Coventry and other large cities and key strategic areas. The service struggled. Midwife shortages were rife and staff were often in the wrong place at the wrong time, as demand could not be predicted with any great level of accuracy. The Ministry of Health correspondence is awash with letters from the receiving areas desperate for staff. There were other challenges too. Billets for those awaiting hospital admission became increasingly hard to find for the expectant mothers, as they were a particularly unpopular group with host households. Not only were pregnant woman seen as a troublesome type of evacuee with which to share a home, but rates of compensation provided to householders from the government for housing a pregnant woman was also far lower than that for other groups.

Nevertheless, there were 10,500 confinements in the Emergency Maternity Homes in 1940. This number almost tripled in 1941 when there were almost 28,000 confinements, despite less bombing throughout the year over all. What this reveals is that women were beginning, at this stage, to see the service as something other than it is. Expectant mothers were leaving London for their confinements in droves, despite a lesser threat of bombing. The reasons for this become clear upon examination of the data. The archive material reveals that the London boroughs were simply unable to meet the demand for either home or hospital births. Partly this was because of bed shortages. Numbers of hospitals had been destroyed and the upper floors of those still functioning were closed because of fears of further bomb damage. Midwifery staff had also been relocated to the country maternity homes in the reception areas Thus, the Emergency Maternity Service stepped into the national breech as local community maternity services were lacking. From April 1942 onwards some1000-1500 women left the evacuation areas per month. As a consequence, the emergency maternity homes became full to overflowing and the London boroughs had to actually cease referrals. In the reception areas there was an increasing tension between the emergency maternity homes and local maternity provision. Technically, local women were not permitted to use the beds in the emergency homes. However, 
where local provision was lacking, women were not left with much in the way of alternative, especially in emergency situations. This, of course, meant that beds meant for evacuated mothers were tied up by local needs, which caused further delays.

In 1942 there was a change in how the scheme was described the government and local authorities. Rather than being promoted as an evacuation scheme it was instead called a 'special scheme of country maternity homes for city mothers'. Since mothers now usually returned home after their 4-week confinement period, the scheme could not easily be justified as an evacuation expense. However, transferring the expense back to local authorities from the national exchequer potentially meant further hardship to mothers, and therefore some embarrassment to a government acting in loco parentis to the nation. Thus, a blind eye was turned and the Emergency Maternity Service continued to be an evacuation scheme financially if nothing else. Bombs were no longer the reason that women were leaving the city to give birth but the maternity beds certainly were.

It could be argued at this point that the Emergency Maternity Service did on national scale what was required at the time. It added approximately 5000 beds to the maternity system which had been strained and patchy at the onset of war. But when examined through the archival data, the narrative is just not that neat. The state stepped into the metaphorical labour room because it needed to protect a particularly vulnerable group at time of war. It stayed there because there was no easy way to withdraw. After putting in a place a system which meant that women could more easily access maternity care, it proved difficult to put the genie back in the bottle. The Ministry of Health tried to finally close the Emergency Maternity Scheme in 1947 but this was met with outcries from the London boroughs who simply had no way of providing enough hospital beds for the women who wanted them. The compromise was that the scheme would continue, but the government would not pay for it.

\section{The Impact of the Emergency Maternity Service}

The trend towards hospital birth had been steadily increasing during the pre-war years. This is illustrated by a steady growth in the number of hospital beds offered to pregnant women: for example, increasing from 7070 beds in 1930 to 9439 in 1939. It is obviously problematic to attempt to capture precise motivations for change for a group as diverse as all pregnant women. However, the move can be linked to arguments for an increased 'hospital consciousness' in all forms and combined with an element of the hospital birthing 'trend' such as the rise in demand for pain relief. As Mass-Observation noted, pain relief and better conditions were high on women's list of priorities. Yet it must be born in mind that many working-class women did not wish to go to hospital at all, even if it was advised. This was partly based on tradition, partly on the sigma still present regarding local authority hospitals, and partly, too, because there were often other children at home who needed to be looked after (Pickstone 1985). Yet as Elizabeth Roberts notes, women were also becoming less fatalistic about childbirth, and more willing to seek qualified intervention (Roberts 1984). It was a complex picture. Whatever may be gleaned about motivations behind changes in birth location, the fact is that hospital births did rise. In 1919 there were a total of 1360 beds in maternity homes and hospitals in England and Wales and by 1939 there were 4070. Through the drastic halt of the provision for home births during the war, this general trend was intensified. In 1944, 41,248 confinements were in the Emergency Maternity Homes out of 751,000 births in England and Wales, a 390\% increase on the 1940 figure. There were of course material issues such as bombdamaged housing and subsequent overcrowding, family displacement and the mothers unable to find help and support. In this respect it was the very war itself that was shaping the birthing experience. Nevertheless, the establishment of the Emergency Maternity Service assisted in the removal of the option for home birth for many women during wartime by removing community midwifery staff from evacuation and reception areas in order to staff the emergency homes. By 1948 there were 18,786 maternity beds in England and Wales.

When the war was over and the Ministry of Health fully expected women to return to giving birth back at home. It found itself sorely mistaken. England and Wales had got a taste for hospital births and there was no going back. The Cranbrook Report of 1959 stated that hospital maternity services were to provide for $70 \%$ of births, and in the 1960 s hospitalisation of birth accelerated so that 
by 1970 nearly $90 \%$ of births occurred within hospitals. In 1970 the Peel report stated that facilities should be provided for all women to give birth in hospital, based largely on findings from the Reports of the Confidential Enquiry into Maternal Deaths which claimed home births were dangerous. This led rapidly to over $95 \%$ of women giving birth in a hospital setting. By the 1980 s, less than $1 \%$ of births took place in the home.

\section{Conclusion}

During the Second World War the government decided to protect the future of the British nation by evacuating expectant mothers and children. This decision had an impact on the experience of pregnant women throughout the country. If women stayed in at risk areas, there were very few maternity beds for them to access and little to no district midwives. If they evacuated they had to leave existing children at home or in the care of wartime day nurseries. War displaced their support networks, husbands were away, sisters and friends were enlisted, and if they went to the emergency maternity homes they would at least receive care and support and be compelled to rest for two weeks following the birth. Pregnant women in wartime had very little agency over their birth experience, but arguably, they had very little before the war. What did occur was that the state had put in place maternity care structures that meant women could access. While the state was not prepared for the post-war demand for institutional confinement to grow at such a rate as to eliminate the practice of home birth almost entirely within three decades, it had already put in place the structures to help this happen. To attempt to get to the source of precise motivations behind this change is to explore the wider issue of a post-war consensus and demand for centralised health and social care as well as delving into the form and existence of post-war communities, which is how this thesis shall progress. However, even in this limited format it is hard to deny that the existence of the Emergency Maternity Service between 1939 and 1948 had an irretrievable impact on the maternity experience of British mothers, an impact that is still felt today.

\section{Primary Material}

Annual Reports of the Medical Officer of Health 1918-1944, Nottingham Local Studies Library.

Mass Observation File 1921, 'Public Attitudes to State Medicine', pp. xi, 97, 103.

Nottingham Oral History Collection, A21b, Nottingham Local Studies Library.

National Archives London files: HLG7/259, HLG7/234, HLG7/234, HLG51/1042 MH55/1574, HLG 900/52, MH52/805.

Registrar General's Statistical Review for England and Wales for 1935, (HMSO: London, 1938).

\section{References}

Ferguson, S and H. Fitzgerald. 1954. Studies in the Social Services. London: HMSO.

Ferraby, J. G. 1945. "Observations on the Reluctant Stork.” Public Opinion Quarterly 9(1): 29-37.

Hatton, Timothy, J. and Mark Thomas. 2010. "Labour Markets in the Interwar Period and Economic Recovery in the UK and the USA." Oxford Review of Economic Policy 26(3): 463-485.

Hayes, Nick. 2012. "Did We Really Want a National Health Service? Hospitals, Patients and Public Opinions before 1948." The English Historical Review CXXVII (526): 625-661.

Loudon, Irvine. 1992. Death in Childbirth: An International Study of Maternal Care and Maternal Mortality 1800-1950. Oxford: Clarendon.

Marks, Lara. 1996. Metropolitan Maternity: Maternal and Infant Welfare Services in Early Twentieth Century. London: Editions Rodopi B.V.

McKibbon, Ross. 2000. Classes and Cultures: England 1918-1951. London: Oxford University Press.

Pickstone, John V. 1986. Medicine and Industrial Society: A History of Hospital Development in Manchester and Its Region. Manchester: Manchester University Press.

Roberts, Elizabeth. 1994. A Woman's Place: An Oral History of Working Class Women, 1890-1940. London: John Wiley and Sons.

Sheard, Sally, 2011. "A creature of its time: the critical history of the creation of the British NHS." Michael Quarterly $2011 ; 8: 428-41$.

Titmuss, Richard M. 1950. Problems of Social Policy. London: HMSO. 